\title{
1,3-Dipolar Cycloaddition Reactions of Pyridinium Azomethine Ylides Containing 5,6-Dicyanopyrazines
}

\author{
Jae-yun Jaung" and Young-Sik Jung" \\ ${ }^{\dagger}$ Department of Polymer \& Textile Engineering, Hanyang University. Seoul 133-791. Korea \\ Medicinal Science Division. Korea Research Institute of Chemical Technology, P.O. Box 107, Yusong, Daejeon 305-606, Korea \\ Received July 25,2003
}

Key Words : Azomethine ylides. Dicyanopyrazine. Dipolar cycloaddition

The intermolecular 1,3-dipolar cycloaddition reaction of azomethine ylides with carbon-carbon double or triple bonds represents an efficient and convergent method for the construction of heterocyclic structures containing a single nitrogen atom. ' One of the most frequently employed methods for the generation of azomethine ylide involves the thermolysis of an aziridine. ${ }^{2}$ However, the ring opening of aziridines to azomethine ylides is limited to those having substituent groups capable of stabilizing the dipole centers. Desilylation of $\alpha$-trimethylsilylonium salts represents another convenient method of generating azomethine ylide." More recently it has been found that nonstabilized azomethine ylides can be generated by the deprotonation of amine $\mathrm{N}$ oxides." Azomethine ylides are too unstable to be isolated. and are typically used in sith. Of the various types of azomethine ylides, the pyridinium azomethine ylides are among the most attractive synthetically because they are easily prepared from the appropriate $\mathrm{N}$-alkylpyridinium salt with base and their cycloadducts, the indolizines, have been used as synthetic building blocks."

In our continuing efforts to develop functional dyes based on dicyanopyrazine chromophores, we have become interested in pyridinium azomethine ylides containing dicyanopyrazines and their 1,3-dipolar cycloaddition reaction with dipolarophiles, because the indolizine cycloadducts, containing dicyanopyrazines, might meet our purpose. Dyes and pigments generally possess satisfactory color, and good color fastness properties against light and heat, and additional properties such as near infrared absorption, pleochroism, and photoconductivity." The majority of these properties are catused by intramolecular charge-transfer interactions involving $\pi$-electrons and intermolecular $\pi-\pi$ interactions of the dye chromophores. ${ }^{7}$

In this paper, we report the generation of pyridinium azomethine ylide intermediates and the results of 1,3-dipolar cycloaddition reactions of the ylides with dipolarophiles to provide indolizines containing 5,6-dicyanopyrazine. The preparation of methyl or phenyl substituted 2-bromomethyl5.6-dicyanopyrazine $\mathbf{I}$ is described in a previous report. ${ }^{6 b}$ Treatment of methyl substituted pyridine 2 with 1.0 equiv of pyrazine methylbromide 1 under toluene reflux afforded (5.6-dicyanopyrazine) methyl pyridinium bromide 3 in 70 $79 \%$ yield (Scheme 1). ${ }^{8}$ The generation of ylide 4 in situ from 3 followed by the cycloaddition of 4 with dimethyl acetylenedicarboxylate (DMAD), one of the most reactive dipolarophiles, was attempted. To a mixture of the salt $\mathbf{3}$ with DMAD in benzene was added $F_{\mathrm{t}} \mathrm{t}_{\mathrm{i}} \mathrm{N}$, and the mixture was turned to a dark purple and produced indolizines 5 in $40-55 \%$ vields."

Although azomethine ylides are generally unstable species, which must be prepared and used in situ, we found that the ylides are quite stable in solution. Thus, the isolation of the ylide 4 was attempted. Treatment of 3 with acyueous sodium hydroxide in acetonitrile provided the dark red colored ylide 4 as a solid. ${ }^{8}$ The formation of the ylide 4 was veritied with ${ }^{1} \mathrm{H}$ NMR spectroscopy. For example, conversion of the

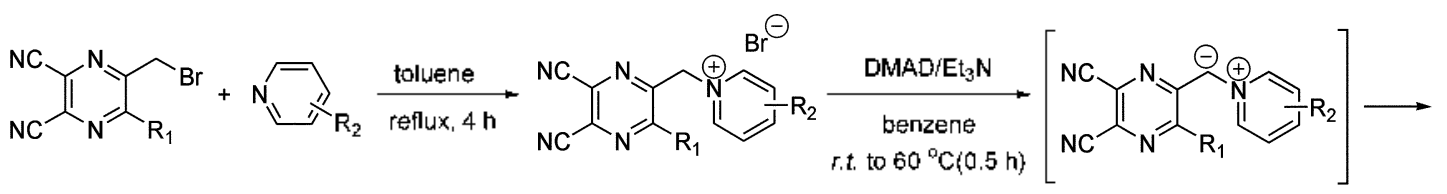

1 2

1a $\mathrm{R}_{1}=\mathrm{CH}_{3}$

b $\mathrm{R}_{1}=\mathrm{Ph}$

4

$$
\begin{array}{rlrl}
2 a & \mathrm{R}_{2} & =\mathrm{H} \\
\mathbf{b} & \mathrm{R}_{2} & =2-\mathrm{CH}_{3} \\
\text { c } & \mathrm{R}_{2}=4-\mathrm{CH}_{3}
\end{array}
$$

\begin{tabular}{c|cc} 
3, 4,5 & $\mathrm{R}_{1}$ & $\mathrm{R}_{2}$ \\
\hline $\mathbf{a}$ & $\mathrm{CH}_{3}$ & $\mathrm{H}$ \\
$\mathbf{b}$ & $\mathrm{CH}_{3}$ & $2-\mathrm{CH}_{3}$ \\
c & $\mathrm{CH}_{3}$ & $4-\mathrm{CH}_{3}$ \\
d & $\mathrm{Ph}$ & $\mathrm{H}$ \\
e & $\mathrm{Ph}$ & $4-\mathrm{CH}_{3}$
\end{tabular}

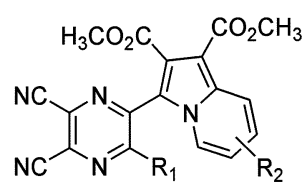

5 

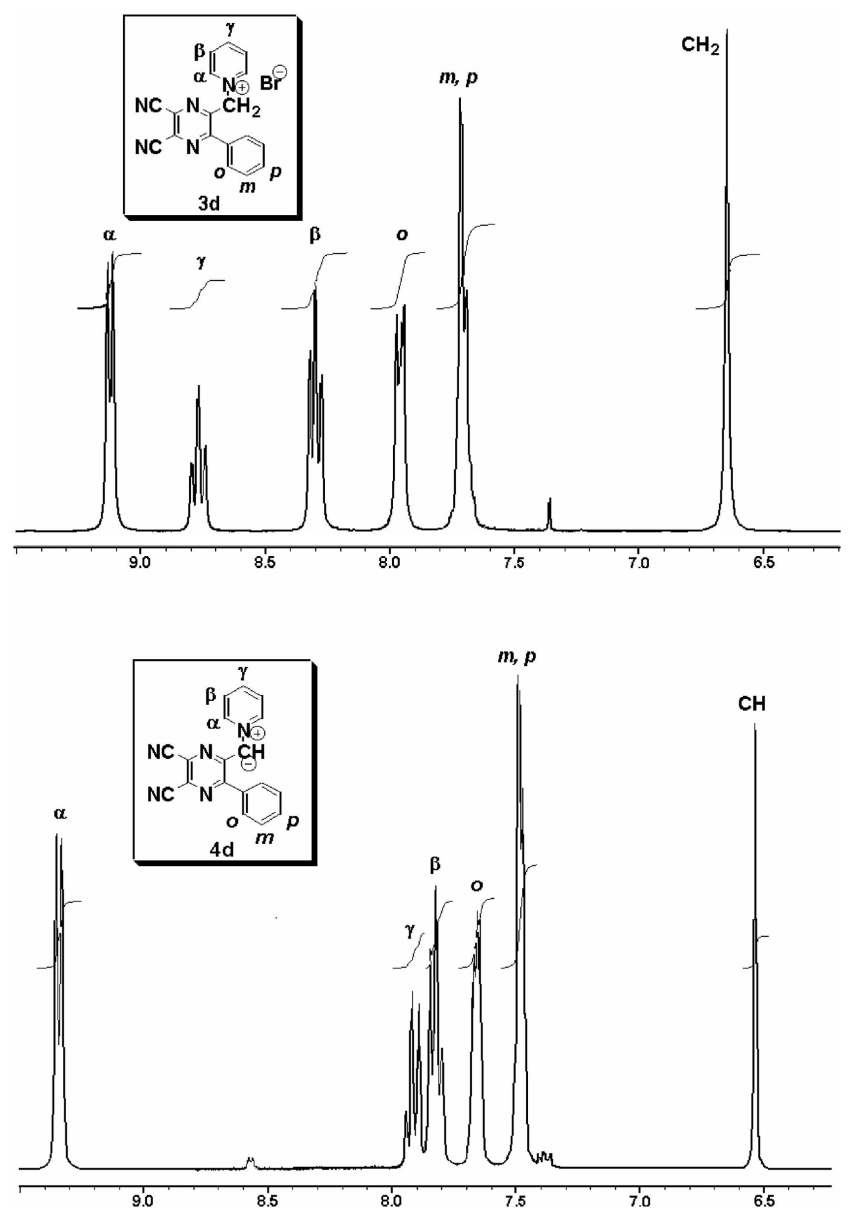

Figure 1

pyridinium bromide $\mathbf{3 d}$ into the ylide $\mathbf{4 d}$ causes a down field shift of $\alpha$-pyridine protons from $\delta 9.12$ to $\delta 9.34$, and up field shifts of $\beta$-pyridines from $\delta 8.29$ to $\delta 7.82$ and $\gamma$ pyridine proton from $\delta 8.76$ to $\delta 7.91$ (Figure 1). In the chemical shifts of $\mathrm{C}-\mathrm{H}$ protons, the $\mathrm{CH}_{2}$ of $\mathbf{3 d}$ and the $\mathrm{CH}$ of 4d appear at $\delta 6.64$ and $\delta 6.53$, respectively. Similar observation of the chemical shifts in 'H NMR has been reported recently. ${ }^{10}$

Another 1,3-dipolar cycloaddition reaction of $4 \mathbf{d}$ with methyl acrylate was attempted and indolizine 6 was obtained in $37 \%$ yield after flash column chromatography (Scheme 2). According with electronic factor, the cyclization reactions of $4 \mathbf{d}$ proceeds to yield 6 instead of the other possible regioisomer. In the case of the preparations of 5 and $\mathbf{6}$, the intermediates, dihydroindolizines and tetrahydroindolizine. were not stable enough to be isolated.

In summary, we carried out the 1,3-dipolar cycloaddition reactions of the pyridinjum azomethine ylides with DMAD and methyl acrylate as dipolarophiles to provide indolizines containing 5,6-dicyanopyrazines in moderate yields. The pyridinium azomethine ylide $\mathbf{4 d}$ was isolated and identified by ${ }^{1} \mathrm{H}$ NMR.<smiles>CCOC(=O)c1cc(-c2nc(-c3ccccc3)c(C#N)nc2-c2ccccc2)n2ccccc12</smiles>

Scheme 2

Acknowledgment. This work was supported by grants from the Ministry of Science and Jechnology in Korea and from Korea Science \& Engineering Foundation (R0L -2002000-00117-0).

\section{References and Notes}

1. (a) Lown. J. W. /,3-Lipolo (ciclouddition Chemistm: Padra. A.-

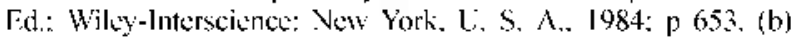

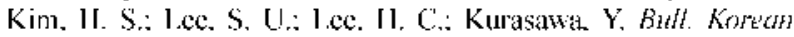
(hem. Soc. 20112, 23,511.

2. (a) Huisgen. R: Mader. H. . .tm. Chem. Soc. 1967. 89. 1753. (b) l'adta. A.: Hamilion. L. Tetrohedron Left. 1965. 6. 4363.

3. (a) Vodejs. E.: West. F. G. J. Org. Chem. 1983. 48. 4773. (b) Vedcjs. F.: Martinus. (i, R. J. Am. (hem. Soc. 1980. 102.7993. (c) Vedejs. F.: I arsem, S.: West. F. G.J. Org. (hem. 1985, 50, 2170.

4. Chastanel. J.: Roussi. (i. J. Org (hem. 1988, 53. 3808 .

5. (a) Malsuda, Y.: Gotou. M.: Yamashita M.: Takahashi. K.: Ide. S.: Furumo. K.: lorisu. K.: Itou. I.: Molokata. C. Heteroceles 1992. 34. 2277. (b) Matsutmoto. K.: Llchida. T.: Aoyatma. K.: Nishikawa. M.: Kuroda. T.: Okamoto. T. J. Heteroclefic Chem. 1988. 25. 1793. (c) Miki. Y.: Ilachiken. I1.: Yoshikawa, M.: Takimura S.: Ikeda. M. Heterocyctes 1991, 32.655.

6. (a) Jatung. I. Y.: Matsuoka. .1.: I ukunishi. K. Dres and Pigments 1997. 34. 255. (b) Jaung. I. Y.: Malsuoka. M.: Fukunishi. K. Dres and Pigments 1998. 36. 395. (c) Jaung. I. Y.: Matsuoka. M.: Fukutishi. K. Dres athd Pigments 1998. 37.135.

7. These compounds will be candidate for nonlinear optical (NI.O) materials beacuse they produce a large dipole moment in the exciled state. They have strong lluorescence in solution and some have strong tluoresonce even on solid state. These characteristics are very important to evaluate thejr NLO and clectroluminescestec propertics.

8. Jaung J. Y.: Fukunishi. K.: Kim, S. D.: Jeong. S. II.: Kim. S. II, f.

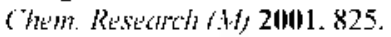

9. Typical procedure for I._-i-dipolar cycloaddition reactions of the pyridinium bromide 3 with DMAD: lo a mixlure of 3 a $(37$ mg. $0.11 \mathrm{mmol}$ ) and D.MAD (25 $\mathrm{mg} .0 .17 \mathrm{mmol}$ is antwdrous botizetic (3 mL) was added $\mathrm{Et}_{\mathrm{i}} \mathrm{V}$ (18 $\left.\mathrm{mg} .0 .17 \mathrm{mmol}\right)$, and the mixture was heated at $60{ }^{\circ} \mathrm{C}$ for $0.5 \mathrm{~h}$. Concentration of the mixture under reduced pressure aflorded a crude product. which was purilied by lash chromalography t silica gel. hexame : Fionc

$2: 1)$ to provide 5 a $(21 \mathrm{mg} .50 \%$ ) as a yellow solid. for analytical data. the solid was recrystal]ized from methanol to give 5 as a ycllow crystal. mp 192-193 "C: 'H VMR (200 MHz.

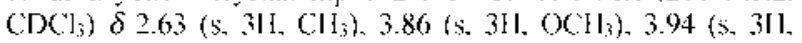
$O\left(\mathrm{H}_{3}\right) .6 .94$ (ddd. $\left.f=7.2 .6 .8 .1 .2 \mathrm{Il} .1 \mathrm{HI} . \mathrm{ArH}\right) .7 .3 \mathrm{l}$ (ddd. $f=$ 9.2. 6.8. 1.0 H \%. III. ArH). 8.03 (dt. $J=7.2 .1 .0 \mathrm{HI} . . \mathrm{II} . \wedge \mathrm{rH})$. 8.30 (dt. $J$ 9.2.1.2 Hz. lH. ArH): EIMS $n=$ (rel. intensity) 375 $\left(\mathrm{M}^{-} .87\right) .344(100) .312(90) .284(31) .257(46)$.

10. Dega-Szafran. Z.: Schrocder. Ci.: Szafran. M.: Szwajea. A.: Leska. B.: 1.ewandowska, M. J. Afol. Strutct. 2000. 555.31 . 